\title{
Concordância na deteç̧ão de anticorpos anti-Toxoplasma gondii e anti-Neospora caninum no sangue e no leite bovino pela reação de imunofluorescência indireta
}

\author{
Agreement in detection of antibodies against Toxoplasma gondii and Neospora \\ caninum in blood and milk of cattle by indirect fluorescent antibody test
}

\author{
Andréa Christina Ferreira Meirelles ${ }^{\mathrm{I}^{*}, \text { II }}$ Rosangela Locatelli-Dittrich $^{\mathrm{I}}$ \\ Bruno Castilhos ${ }^{\text {III }}$ Ana Paula Brenner Busch ${ }^{\mathrm{I}}$
}

\section{RESUMO}

O objetivo deste estudo foi avaliar a aplicabilidade da pesquisa de anticorpos anti-Toxoplasma gondii $e$ antiNeospora caninum em amostras de leite bovino pela reação de imunofluorescência indireta (RIFI) e sua concordância com a detecção desses anticorpos em amostras de soro sanguíneo, simultaneamente coletadas das mesmas vacas. No total, foram analisadas amostras correspondentes de soro sanguíneo e de leite de 177 vacas em início de lactação. Para o T. gondii, o diagnóstico no leite demonstrou concordância boa e sensibilidade baixa, quando comparado ao soro sanguíneo com título de anticorpos séricos $\geq 64$ (ponto de corte). Quanto ao N. caninum, obteve-se concordância excelente entre a detecção de anticorpos no soro sanguíneo com título $\geq 50$ (considerado ponto de corte para termos de diagnóstico) e no leite, com sensibilidade de $80,7 \%$ e especificidade de $100 \%$, no entanto, para as vacas com títulos de anticorpos $\geq 100$ no soro sanguíneo, a sensibilidade e a especificidade foram de 100\%. Nas condições do presente estudo, demonstrou-se que a RIFI não é indicada para diagnóstico da toxoplasmose em amostras de leite bovino, devido ao alto percentual de vacas soropositivas para anticorpos anti-T. gondii no soro sanguíneo diluído 1:64, em cujas amostras de leite não houve detecção desses anticorpos. Por outro lado, a RIFI é um teste viável para o diagnóstico da neosporose bovina, especialmente considerando como ponto de corte um título de anticorpos séricos $\geq 100$, podendo ser recomendável pela praticidade de coleta da amostra como parte de programas de saúde dos rebanhos e estudos epidemiológicos.

Palavras-chave: RIFI, sorologia, neosporose, toxoplasmose, vacas leiteiras.

\section{ABSTRACT}

This study aimed to evaluate: the applicability search for anti-Toxoplasma gondii and anti-Neospora caninum antibodies in cattle milk samples by indirect fluorescent antibody test (IFAT), and their concordance with detection of the same antibodies in blood serum samples, simultaneously collected from the same cows. A total of 177 cows in the beginning of lactation provided corresponding samples of blood serum and milk. To T. gondii, milk diagnosis demonstrated good conformity and low sensitivity in comparison with blood samples whose serum antibody titer ranged $\geq 64$ (cut-off point). As for $\mathbf{N}$. caninum it was obtained optimum conformity between the detection of blood serum antibodies, with titer ranging $\geq 50$ (diagnose-aimed cutoff point) and milk, with sensitivity reaching $80.7 \%$ and $100 \%$ specificity. However, sensitivity and specificity reached $100 \%$ for cows whose antibodies titers in blood serum ranged $\geq 100$. The study was able to demonstrate that IFAT is not indicate to diagnose toxoplasmosis in cattle milk samples due to the high percentage of cows that showed seropositivity to anti-T. gondii antibodies at the 1:64 blood serum dilution, in whose blood samples there was no such antibody detection. On the other hand, IFAT is a feasible test for diagnosing cattle neosporosis, especially when cut-off point is a serum antibody titer $\geq 100$. It can be recommended as part of herd health programs and epidemiologic studies due to sampling practicality.

Key words: IFAT, serology; dairy cattle, neosporosis, toxoplasmosis.

\section{INTRODUÇÃO}

Toxoplasma gondii e Neospora caninum são parasitos intracelulares obrigatórios e podem acometer diversas espécies relevantes na produção de leite e seus derivados, como ovinos, caprinos, bovinos e bubalinos (DAGUER et al., 2004; DUBEY \& SCHARES, 2011). Ambos parasitas são importantes

\footnotetext{
'Programa de Pós-graduação em Ciências Veterinárias, Universidade Federal do Paraná (UFPR), Rua dos Funcionários, 1540, 80035-050, Curitiba, PR, Brasil. E-mail: acmeirelles@gmail.com.*Autor para correspondência.

"Pontifícia Universidade Católica do Paraná (PUCPR), Toledo, PR, Brasil.

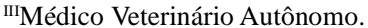


causas de problemas reprodutivos, isolados ou associados a outros agentes (DUBEY, SCHARES \& ORTEGA-MORA, 2007). O impacto econômico global da neosporose bovina foi avaliado recentemente e o aborto é o principal fator de prejuízo ao produtor. Em 10 países avaliados, as perdas econômicas devido ao $N$. caninum na bovinocultura excedem um bilhão de dólares anuais (REICHEL et al., 2012). No Brasil, infecções por $\boldsymbol{T}$. gondii trazem prejuízos tanto para a saúde pública quanto para o setor agropecuário. Há relatos de infecção por $\boldsymbol{T}$. gondii em diversas espécies animais, inclusive aquelas que são utilizadas para consumo humano, podendo causar a toxoplasmose humana (DAGUER et al., 2004; COSTA et al., 2009).

O diagnóstico da neosporose e toxoplasmose bovinas pode ser realizado pela detecção do parasita por histopatologia, imunohistoquímica ou por PCR, ou pela detecção de anticorpos contra o parasita por ensaio imunoenzimático (ELISA), soroaglutinação ou reação de imunofluorescência indireta (RIFI), sendo a RIFI considerada uma técnica específica e de referência para ambos os parasitas (REMINGTON et al., 2004; DUBEY \& SCHARES, 2011). A pesquisa de anticorpos em amostras de leite é um método utilizado na Europa para investigação, monitoramento e controle de doenças infecciosas em rebanhos bovinos. O estado sanitário do rebanho pode ser avaliado no leite em relação à brucelose, diarreia viral bovina (BVD) e Leptospira hardjo (MILNE et al., 2006). A detecção de anticorpos anti- $\boldsymbol{N}$. caninum em amostras individuais de leite, pela técnica de ELISA, tem sido utilizada em alguns países desde 1999 (CHANLUN et al., 2006; MILNE et al., 2006; GONZÁLEZ-WARLETA et al., 2011). Por outro lado, a RIFI, embora seja considerada um teste padrão para diagnóstico sorológico de Neospora spp., é pouco estudado para detecção de anticorpos anti-N. caninum no leite (OOI et al., 2000; CAMILLO et al., 2010).

No Brasil, há estudos avaliando a concordância entre a detecção de anticorpos anti- $\boldsymbol{N}$. caninum, em amostras de soro sanguíneo e do leite individual de fêmeas bovinas, somente no Rio Grande do Sul (CAMILLO et al., 2011). Em toxoplasmose, os relatos de detecção de anticorpos no leite são limitados, sendo relatados em ratas, cabras e ovelhas (VITOR et al., 1991; COSTA \& LANGONI, 2010). Em bovinos, no Brasil, não existem estudos que associem a ocorrência de anticorpos no soro sanguíneo e no leite para $\boldsymbol{T}$. gondii. Os testes para detectar anticorpos anti-T. gondii e $\boldsymbol{N}$. caninum no leite poderiam ser mais utilizados, porém, as informações a respeito do método da RIFI para este tipo de análise em bovinos são limitadas até o presente (COSTA
\& LANGONI, 2010; CAMILLO et al., 2011). O objetivo deste estudo foi avaliar a aplicabilidade da pesquisa de anticorpos anti-Toxoplasma gondii e anti-Neospora caninum em amostras de leite bovino pela reação de imunofluorescência indireta (RIFI) e sua concordância com a detecção desses anticorpos em amostras de soro sanguíneo, simultaneamente coletadas das mesmas vacas.

\section{MATERIAL E MÉTODOS}

No presente estudo, foram coletadas 177 amostras simultâneas de sangue e de leite de vacas em fase inicial de lactação, procedentes de 10 propriedades rurais, localizadas nas mesorregiões Centro-Sul (três), Oeste (cinco) e Sudoeste (duas) do estado do Paraná. As amostras de sangue foram coletadas por punção da veia coccígea e centrifugadas a $1000 x g$ por $10 \mathrm{~min}$ para obtenção do soro sanguíneo. As amostras de soro foram mantidas a $-20^{\circ} \mathrm{C}$ até as análises. As amostras de leite foram coletadas de maneira asséptica, em tubos de ensaio estéreis e obtidas de quartos sem mastite clínica. Os três primeiros jatos de leite foram desprezados e as amostras foram mantidas refrigeradas para transporte até o laboratório. O leite foi centrifugado a 1000xg durante 20 minutos; a amostra para análise foi aspirada abaixo da camada de gordura e mantida a $-20^{\circ} \mathrm{C}$ até as análises (OOI et al., 2000; CAMILLO et al., 2011).

Cada amostra de soro sanguíneo foi dividida em duas alíquotas nas diluições iniciais de 1:64 e 1:50 (PBS, pH7,2), destinadas para a RIFI contra $\boldsymbol{T}$. gondii ou $\boldsymbol{N}$. caninum, respectivamente; as amostras de leite foram destinadas a RIFI sem serem diluídas. As amostras de soro sanguíneo que apresentaram reações positivas foram diluídas até a determinação do título máximo da reação (CAMILO et al., 2011; MACEDO et al., 2012). Foram utilizadas lâminas contendo taquizoítos de $\boldsymbol{T}$. gondii (cepa RH) ou $N$. caninum (cepa NC-1), obtidos através de cultura in vitro em células VERO, produzidos no Laboratório de Patologia Clínica da UFPR. Os taquizoítos foram diluídos para uma concentração de 500 a 1000 taquizoítos $\mu^{l^{-1}}$ de PBS e colocados em lâminas forradas com teflon, contendo 12 poços de $5 \mathrm{~mm}$ de diâmetro cada, as quais foram secas em estufa a $37^{\circ} \mathrm{C}$ e conservadas a $-20^{\circ} \mathrm{C}$ até as análises. Amostras de soro sanguíneo de bovinos, positivas ou negativas, foram utilizadas como controle para a RIFI em todas as lâminas, assim como anticorpo secundário anti-IgG $^{\Theta a}$ bovino conjugado ao isotiocianato de fluoresceína na diluição de 1:100. As amostras com fluorescência periférica total do taquizoíto foram consideradas positivas (PARÉ et al., 1995). 
As amostras de soro sanguíneo e de leite foram testadas paralelamente. Os resultados da detecção de anticorpos nos diferentes fluidos testados foram comparados, utilizando-se o resultado da RIFI no soro sanguíneo como referência. Foram calculados os valores de sensibilidade, especificidade e concordância (índice kappa) seguindo as recomendações da OPAS (1997). A sensibilidade e a especificidade da detecção de anticorpos pela RIFI no leite foram calculadas em comparação à detecção de anticorpos nas amostras de soro sanguíneo.

\section{RESULTADOS E DISCUSSÃO}

Os resultados de concordância entre o título de anticorpos no sangue e no leite, pelo índice kappa para $\boldsymbol{T}$. gondii e $\boldsymbol{N}$. caninum, estão apresentados nas tabelas 1 e 2 , respectivamente. Nas vacas que apresentaram título de anticorpos anti- $\boldsymbol{T}$. gondii de 1:64 no soro sanguíneo, foi encontrada boa concordância (índice kappa 0,62), com sensibilidade de $51,3 \%$ e especificidade de $100 \%$ nas amostras de leite correspondentes. Nas amostras de soro sanguíneo, com título de anticorpos de 256 e 1024 , obteve-se sensibilidade e especificidade de $100 \%$ e concordância excelente.

O total de vacas positivas para anticorpos contra $\boldsymbol{T}$. gondii no soro sanguíneo diluído a 1:64 foi de 37, porém, 19 dessas vacas não tiveram anticorpos anti-T. gondii detectados no leite. O índice kappa demonstrou concordância boa e sensibilidade considerada baixa para a detecção comparativa de anticorpos contra $\boldsymbol{T}$. gondii no soro sanguíneo e no leite nesta diluição. Estes resultados depõem contra a segurança do diagnóstico sorológico para $T$. gondii em amostras de leite bovino pela RIFI. Considerando que, em geral, preconizam-se diluições sorológicas com ponto de corte $\geq 64$ (MARANA et al., 1994;
GARCIA et al., 1999; DAGUER et al., 2004), estes resultados discordantes são particularmente relevantes do ponto de vista diagnóstico, uma vez que 51,35\% das vacas soropositivas para anticorpos contra $\boldsymbol{T}$. gondii, na diluição de 1:64 do soro sanguíneo, seriam consideradas negativas pela RIFI, utilizando amostras de leite, incorrendo-se em resultados falso-negativos quanto ao status sorológicos destes animais.

A utilização da RIFI para detecção de anticorpos contra o $\boldsymbol{T}$. gondii no leite bovino e sua relação comparativa com amostras de soro sanguíneo são temas ainda pouco explorados em bovinos. Analisando os resultados das amostras de soro sanguíneo e de leite para o T. gondii, observou-se que a frequência de animais com anticorpos detectáveis no leite aumenta conforme o título no soro, possivelmente devido aos níveis de imunoglobulinas no leite serem influenciados pelo nível de anticorpos presentes no soro sanguíneo (HURLEY \& THEIL, 2011).

As imunoglobulinas no leite são influenciadas pelos níveis de anticorpos no soro, mas também são produzidas no úbere, antes do parto, e o nível de IgG diminui rapidamente durante as duas primeiras semanas de lactação (CHANLUN et al. 2006; HURLEY \& THEIL, 2011). Outros fatores que podem alterar o título de anticorpos no leite são: a fase da lactação; alta produção leiteira diária; ocorrência de inflamação da glândula mamária; número de lactações; e o estresse (CHANLUN et al., 2006). No presente estudo, todas as amostras reagentes no leite foram provenientes de animais soro reagentes e o leite foi coletado de quartos que não apresentavam mastite clínica, o que indica possivelmente a ausência de reações falso-positivas no leite, que, de acordo com KLINTEVALL e colaboradores (1991), poderiam ser causadas por mastite ou resíduos de gordura. Neste caso, a necessidade de identificar quartos mamários sem indícios de mastite, para detecção de anticorpos

Tabela 1 - Comparação entre o título de anticorpos anti-Toxoplasma gondii em amostras de soro sanguíneo e a detecção qualitativa de anticorpos em amostras de leite, coletadas simultaneamente das mesmas vacas e avaliadas pela reação de imunofluorescência indireta (RIFI).

\begin{tabular}{lccc}
\hline $\begin{array}{l}\text { Títulos de anticorpos no soro } \\
\text { sanguíneo }\end{array}$ & $\begin{array}{c}\text { № de vacas positivas no soro } \\
\text { sanguíneo/No total de amostras } \\
\text { sanguíneas }(\%)\end{array}$ & $\begin{array}{c}\text { № de vacas positivas no } \\
\text { leite/total de positivas no soro } \\
\text { sanguíneo }\left(\%, \kappa^{\mathrm{a}}\right)\end{array}$ & $\begin{array}{c}\text { Bom } \\
\text { Critério }\end{array}$ \\
\hline 64 & $37 / 177(20,9)$ & $19 / 37(50,3 ; 0,62)$ & Excelente \\
1024 & $17 / 177(9,6)$ & $17 / 17(100 ; 1,00)$ & Excelente \\
\hline
\end{tabular}

ándice kappa $(\kappa)$

*Critério de classificação - concordância estatística em nível de 5\% entre os resultados avaliados, pelo índice kappa (ROSNER \& WILLETT, 1988). 
Tabela 2 - Comparação entre o título de anticorpos anti-Neospora caninum em amostras de soro sanguíneo e a detecção qualitativa de anticorpos em amostras de leite, coletadas simultaneamente das mesmas vacas e avaliadas pela reação de imunofluorescência indireta (RIFI).

\begin{tabular}{lccc}
\hline $\begin{array}{l}\text { Títulos de anticorpos no soro } \\
\text { sanguíneo }\end{array}$ & $\begin{array}{c}\mathrm{N}^{\mathrm{o}} \text { de vacas positivas no soro } \\
\text { sanguíneo/No total de amostras } \\
\text { sanguíneas }(\%)\end{array}$ & $\begin{array}{c}\mathrm{N}^{\mathrm{o}} \text { de vacas positivas no } \\
\text { leite/total de positivas no soro } \\
\text { sanguíneo }\left(\%, \kappa^{\mathrm{a}}\right)\end{array}$ & $\begin{array}{c}\text { Critério }^{*} \\
50\end{array}$ \\
100 & $83 / 177(46,9)$ & $67 / 83(80,7 ; 0,82)$ & Excelente \\
200 & $63 / 177(35,6)$ & $63 / 63(100 ; 1,00)$ & Excelente \\
400 & $21 / 177(11,9)$ & $21 / 21(100 ; 1,00)$ & Excelente \\
800 & $12 / 177(6,8)$ & $12 / 12(100 ; 1,00)$ & Excelente \\
\hline
\end{tabular}

aíndice kappa $(\kappa)$.

*Critério de classificação - concordância estatística em nível de 5\% entre os resultados avaliados, pelo índice kappa (ROSNER \& WILLETT, 1988).

pode ser um fator complicador para utilização do diagnóstico desses agentes a partir de amostras de leite, limitando a utilização do teste em animais com alterações inflamatórias da glândula mamária.

Foram detectados anticorpos contra $N$. caninum no soro sanguíneo diluído a 1:50 em 83/177 $(46,9 \%)$ vacas. Destas 83 vacas soropositivas, 67 $(80,7 \%)$ foram positivas também para amostras de leite, com concordância considerada excelente (kappa $=0,82$ ), sensibilidade de $80,7 \%$ e especificidade de $100 \%$. Os resultados obtidos foram superiores aos de CAMILLO et al. (2011), que, em estudo similar, obtiveram concordância de 0,40 no mesmo título. De acordo com CHRISTENSEN \& GARDNER (2000) e CHANLUN et al. (2006), esta diferença entre concordâncias poderia ser justificada pelos contrastes de ecossistemas entre as regiões estudadas, o estádio de lactação, a amostragem ou a produção de leite diária, o que pode interferir no título de anticorpos contra $N$. caninum no leite.

Por sua vez, quando consideradas as amostras de soro sanguíneo com título de anticorpos $\geq 100$, obteve-se concordância excelente, sensibilidade e especificidade de $100 \%$ em relação às amostras de leite. Esses valores corroboram aqueles obtidos por OOI et al. (2000), que utilizaram amostras de leite de vacas com título de anticorpos de 1:200 no soro sanguíneo e obtiveram concordância excelente para a RIFI no leite e no soro sanguíneo. Também confirmam os de CAMILLO et al. (2011), que demonstraram $100 \%$ de concordância entre a RIFI, no soro e no leite, para os animais com títulos de anticorpos séricos $\geq 100$.

Todas as amostras avaliadas para $N$. caninum que foram positivas no soro sanguíneo e negativas no leite $(16 / 83 ; 19,3 \%)$ tinham titulação sérica de $50(\mathrm{k}=0,82)$. A diluição de $1: 50$ no soro sanguíneo é utilizada como ponto de corte para diagnóstico de neosporose por vários autores (DUBEY et al., 2011). Outros estudos realizados, que utilizaram a RIFI para detecção de anticorpos no leite, comparativamente ao soro sanguíneo (OOI et al., 2000; CAMILLO et al., 2011), também verificaram concordância de $100 \%$ entre soro sanguíneo e leite somente em vacas com título de anticorpos séricos $\geq 100$, o que indica que o diagnóstico de neosporose pela RIFI no leite pode ser utilizado, mas com restrições, principalmente em vacas com títulos séricos de 50. No método de ELISA, para diagnóstico de neosporose no leite, GONZÁLEZ-WARLETA et al. (2011) encontraram resultados de concordância no leite e soro sanguíneo de 97,6\%. Da mesma forma, SCHARES e colaboradores (2005), analisando a adaptação de um ELISA comercial para testar amostras de soro de sangue e de leite, observaram uma excelente concordância entre os resultados das amostras pareadas. Estes resultados, aliados aos do presente estudo, demonstram a viabilidade da pesquisa de anticorpos anti- $\boldsymbol{N}$. caninum em amostras individuais de leite, como alternativa para o diagnóstico de neosporose em rebanhos leiteiros.

\section{CONCLUSÃO}

Nas condições do presente estudo, demonstrou-se que a RIFI não é indicada para diagnóstico da toxoplasmose em amostras de leite bovino, devido ao alto percentual de vacas soropositivas para anticorpos anti-T. gondii no soro sanguíneo diluído 1:64, em cujas amostras de leite não houve detecção desses anticorpos. Por outro lado, a RIFI é um teste viável para o diagnóstico da neosporose bovina, especialmente considerando como ponto de corte um título de anticorpos séricos 
$\geq 100$, podendo ser recomendável pela praticidade de coleta da amostra como parte de programas de saúde dos rebanhos e estudos epidemiológicos.

\section{AGRADECIMENTO}

Ao Conselho Nacional de Desenvolvimento Científico e Tecnológico (CNPq) Edital Universal - Edital MCT/ CNPq n. 014/2011- pelo apoio financeiro.

\section{FONTES DE AQUISIÇÃO}

a- Anti-IgG bovina conjugada à fluoresceína (FITC): Affinity Purified Antibody Fluorescein (Sigma/F-7887), Sigma-Aldrich, USA.

\section{COMITÊ DE ÉTICA E BIOSSEGURANÇA}

Projeto aprovado pelo Comitê de Ética em Pesquisa Envolvendo Experimentação Animal da Universidade Federal do Paraná (UFPR) (protocolo n, 0054/2010).

\section{REFERÊNCIAS}

CAMILlO, G. et al. Anticorpos anti-Neospora caninum em bovinos de leite do sudoeste do Paraná. Arquivos Brasileiros de Medicina Veterinária e Zootecnia, v.62, p.1511-1513, 2010. Disponível em: <http://www.scielo.br/scielo.php?pid=S0102$09352010000600033 \&$ script=sci_abstract\&tlng=pt $>$. Acesso em: 17 fev. 2013.

CAMILlO, G. et al. Detecção de anticorpos anti-Neospora caninum em amostras individuais e coletivas de leite de bovinos pela reação de imunofluorescência indireta (RIFI). Pesquisa Veterinária Brasileira, v.31, p.482-486, 2011. Disponível em: <http://www.pvb.com.br/pdf_artigos/23-06-2011_16-21Vet\%20 976_2161\%20LD.pdf>. Acesso em: 27 jan. 2013. doi: 10.1590/ S0100-736X2011000600004.

CHANLUN, A. et al. Application of repeated bulk milk testing for identification of infection dynamics of Neospora caninum in Thai dairy herds. Veterinary Parasitology, v.136, p.243-250, 2006. Disponível em <http://www.sciencedirect.com/science? $\mathrm{ob}=$ ArticleURL\&_udi=B6TD7-4J022WT-3>. Acesso em: $17 \mathrm{fev}$. 2010. doi:10.1016/j.vetpar.2005.11.025.

COSTA, V.M.; LANGONI, H. Detection of Toxoplasma gondii in the milk of experimentally infected Wistar female rats. Journal of Venomous Animals and Toxins including Tropical Diseases, v.16, n.2, p.368-374, 2010. Disponível em: <http://www.scielo. br/scielo.php?pid=S167891992010000200016\&script $=$ sci arttext\&tlng=es>. Acesso em: 16 fev. 2013. doi: 10.1590/S167891992010000200016

COSTA, G.H.N. et al. Frequência de anticorpos anti-Neospora caninum e anti-Toxoplasma gondii em soros de bovinos pertencentes aos estados de São Paulo e de Minas Gerais. Semina: Ciências Agrárias, v.22, n.1, p.61-66, 2009. Disponível em: <http://www.uel. br/revistas/uel/index.php/semagrarias/article/viewArticle/1992>. Acesso em: 12 jan. 2014. doi: 10.5433/1679-0359.2001v22n1p61.

CHRISTENSEN, J.; GARDNER, I.A. Herd-level interpretation of test results for epidemiologic studies of animal diseases. Preventive Veterinary Medicine, v.45, n.1, p.83-106, 2000.
DAGUER, H. et al. Soroprevalência de anticorpos antiToxoplasma gondii em bovinos e funcionários de matadouros da microrregião de Pato Branco, Paraná, Brasil. Ciência Rural, v.34, n.4, p.1133-1137, 2004. Disponível em: <http://www.scielo.br/ pdf/cr/v34n4/a26v34n4.pdf>. Acesso em: 16 fev. 2013.

DUBEY, J.P. et al. Epidemiology and control of neosporosis and Neospora caninum. Clinical Microbiology Reviews, v.20, n.2, p.323-367, 2007. Disponível em: <http://cmr.asm.org/ content/20/2/323.full>. Acesso em: 02 out. 2013. doi: 10.1128/ CMR.00031-06.

DUBEY J.P.; SCHARES G. Neosporosis in animals: the last five years. Veterinary Parasitology, v.180, n.1-2, p.90-108, 2011. Disponível em: <http://www.sciencedirect.com/science/ article/pii/S0304401711003840>. Acesso em: 16 fev. 2013. doi: 10.1016/j.vetpar.2011.05.03.

GARCIA, J.L. et al. Soroprevalência do Toxoplasma gondii em suínos, bovinos, ovinos e equinos e sua correlação com humanos, felinos e caninos, oriundos de propriedades rurais do norte do Paraná, Brasil. Ciência Rural, v.29, n.1, p.91-97, 1999. Disponível em: <http:// www.scientificcircle.com/pt/96531/soroprevalenciatoxoplasma-gondii-suinos-bovinosovinos/>. Acesso em: $16 \mathrm{fev}$. 2013. doi: 10.1590/S0103-84781999000100017.

GONZÁLEZ-WARLETA, M. et al. Anti-Neospora caninum antibodies in milk in relation to production losses in dairy cattle. Preventive Veterinary Medicine, v.101, n.58-64, 2011. Disponível em: <http://www.sciencedirect.com/science/article/pii/ S0167587711001474>. Acesso em: 16 fev. 2013. doi:10.1016/j. prevetmed.2011.04.019.

HURLEY, W.L.; THEIL, P.K. Perspectives on immunoglobulins in colostrum and milk. Nutrients, v.3, n.4, p.442-474, 2011. Disponível em: <http://www.mdpi.com/2072-6643/3/4/442>. Acesso em: 16 fev. 2013. doi: 10.3390/nu3040442.

KLINTEVALL, K. et al. Evaluation of an indirect ELISA for the detection of antibodies to bovine leukemia virus in milk and serum. Journal of Virology Methods, v.33, p.319-333, 1991.

MACEDO, M.F.S.B. et al. Serum occurrence of anti-Toxoplasma gondii antibodies in dairy cows slaughtered in an abattoir for human consume. Ciência Rural, v.42, n.6, p.1065-1069, 2012. Disponível em: <http://www.scielo.br/scielo.php?script=sci_ arttext\&pid=S0103-84782012000600019\&lng=pt\&nrm=iso >. Acesso em: 16 fev. 2013. doi: 10.1590/S0103-8478201200060001.

MARANA, E.R.M. et al. Ocorrência de anticorpos antiToxoplasma gondii em bovinos de corte, abatidos em matadouros do norte do Paraná - Brasil. Semina: Ciências Agrárias, v.15, n.1, p.38-40, 1994.

MILNE, E. et al. Associations between Neospora caninum specific antibodies in serum and milk in two dairy herds in Scotland. Preventive Veterinary Medicine, v.77, p.31-47, 2006. Disponível em: <http://www.sciencedirect.com/science/article/pii/ S0167587706001413>. Acesso em: 16 fev. 2013. doi: 10.1016/j. prevetmed.2006.06.001

OOI, H.K. et al. Serological survey and first finding of Neospora caninum in Taiwan, and the detection of its antibodies in various body fluids of cattle. Veterinary Parasitology, v.90, n.1, p.4755, 2000. Disponível em: <http://www.sciencedirect.com/science/ article/pii/S0304401700002119>. Acesso em: 16 fev. 2013. doi: 10.1016/S0304-4017(00)00211-9. 
OPAS (ORGANIZAÇÃO PAN-AMERICANA DA SAÚDE). Métodos de investigação epidemiológica em doenças transmissíveis. Brasília, 1997. v.1. 116p. Disponível em: <http:// posstrictosensu.iptsp.ufg.br/uploads/59/original_MetodosdeInvest igacaoEpidemiologica-SegundaEd.pdf>. Acesso em: 16 fev. 2013.

PARÉ, J. et al. Interpretation of an indirectfluorescent antibody test for diagnosis of Neospora sp. infection in cattle. Journal of Veterinary Diagnostic Investigation, v.7, p.273-275, 1995.

REICHEL, M.P. et al. What is the global economic impact of Neospora caninum in cattle - the billion dollar question. International Journal for Parasitology, v.43, n.2, p.133142, 2012. Disponível em: <http://www.ncbi.nlm.nih.gov/ pubmed/23246675>. Acesso em: 26 out. 2013. doi: 10.1016/j. ijpara.2012.10.022.
REMINGTON, S. et al. Recent developments for diagnosis of toxoplasmosis. Journal of Clinical Microbiology, v.42, n.3, p.941-945, 2004. Disponível em: <http://jcm.asm.org/ content/42/3/941.full>. Acesso em: 16 fev. 2014. doi: 10.1128/ JCM.42.3.941-945.2004.

SCHARES, G.; BÄRWALD, A.; CONRATHS, F. J. Adaptation of a Surface Antigen-based ELISA for the Detection of Antibodies Against Neospora caninum in Bovine Milk. Journal of Veterinary Medicine, v.52, n.1, p.45-48, 2005.

VITOR, R.W.A. et al. Eliminação de Toxoplasma gondii através de urina, saliva e leite de caprinos experimentalmente infectados. Arquivos Brasileiros de Medicina Veterinária e Zootecnia, v.43, n.2, p.147-154, 1991. 